\title{
Transcobalamins I and II
}

\section{as Natural Transport Proteins of Vitamin $B_{12}$}

\author{
Charles A. Hall \\ From the Hematology Research Laboratory, Veterans Administration Hospital \\ and the Department of Medicine, Albany Medical College of Union University, \\ Albany, New York 12208
}

A в STRACT There are two conflicting theories of how plasma vitamin $B_{19}\left(B_{12}\right)$ is transported in man: (a) by two distinct transport proteins, transcobalamins I and II (TC I and II), each having a specific role and time of function; and $(b)$ by three active transport proteins, TC I, II, and III, that take up $B_{12}$ randomly in proportion to the unsaturated amounts of each. To test these theories a man was given $1.12 \mu \mathrm{g}, 229 \mu \mathrm{Ci}$, of $\left[{ }^{57} \mathrm{Co}\right] \mathrm{B}_{1}$ mixed with food. Blood samples were taken several times on the 1st day and at lengthening intervals up to day 51. The amount of TC II-B 12 was measured in each sample by: gel filtration and by precipitation with $\left(\mathrm{NH}_{4}\right)_{2} \mathrm{SO}_{4}$. Total serum $\mathrm{R}-\mathrm{B}_{12}$ was then separated into TC I and TC III by: (a) a single step anion exchange system and (b) isoelectric focusing (IEF). As the $B_{1 a}$ was being absorbed, $92-95 \%$ of that in venous blood was carried by TC II. Absolute and percentage transport by TC II declined sharply during the first $24 \mathrm{~h}$; between days 7 and $5120-33 \%$ of the label was on TC II, and the rest was carried by R-type binders. Absolute transport by TC I did not reach a maximum until after day 1 and before day 3. Transport by an $\alpha_{\mathbf{s}}$ R-type binder, TC III, could not be demonstrated. TC I was isoelectrically heterogenous, with the components focusing between $\mathrm{pH} 2.9$ and 3.35. It was concluded that (a) TC II is the dominant carrier of $\mathrm{B}_{12}$ immediately after absorption; (b) maximum transport by $\mathrm{TC}$ I requires the passage of time after absorption; (c) after the absorbed $B_{12}$ reaches equilibrium with the total body $B_{18}$, about one fourth of the plasma $B_{12}$ is carried by TC II and three fourth by TC I; and $(d)$ TC I and TC II are the only functional transport proteins of plasma $\mathrm{B}_{\mathbf{1 2}}$.

Received for publication 28 March 1975 and in revised form 23 June 1975.

\section{INTRODUCTION}

The earliest studies (1-3) of all parts of the plasma transport system of vitamin $\mathrm{B}_{12}\left(\mathrm{~B}_{12}\right)^{1}$ as it operated in vivo both in man and the dog led to the following concepts: Transcobalamin II (TC II), a plasma protein now well identified (4), carries most of the $B_{12}$ as it is first absorbed, whether given in an elemental form or incorporated into food. A portion of the circulating $\mathrm{B}_{12}$, however, continues to be carried by TC II long after absorption (5). Transport of $\mathrm{B}_{12}$ by TC II during the recycling phase became convincingly evident by the lethal consequences of the congenital absence of TC II $(6,7)$; without TC II the affected infants could not transport $B_{12}$ from some tissues into others (8). Most of the $\mathrm{B}_{12}$ circulating in the plasma of man is, however, bound to another distinct transport protein, transcobala$\min I$ (TC I) $(5,9,10)$. A puzzling aspect of the transport system is the failure of TCI to behave like an effective transport protein. Unlike TC II, which delivers $B_{1}$ rapidly, TC $I-B_{12}$ clears slowly from the circulation $(10-12)$. In spite of the fact that TC I carries three fourths of the circulating $B_{12}(5)$, its congenital absence is apparently inconsequential (13).

Recently England et al. (14) observed a third substance, which they refered to as TC III, carrying $B_{18}$ in the early days after absorption. They postulated a transport system consisting of three plasma transport proteins, each picking up free $B_{12}$ in the portal blood more or less in proportion to their unsaturated capacities. This third binder has been described by several investigators over the years but only as an in vitro phenomenon. Some of any $\mathrm{B}_{12}$ added to serum in vitro is bound to TC III, but until the work of England et al., there

${ }^{1}$ Abbreviations used in this paper: $\mathrm{B}_{12}$, vitamin $\mathrm{B}_{12}$; IEF isoelectric focusing; TC, transcobalamin. 
were no studies of a possible true transport function. TC I and TC III as well as several other $B_{12}$ binders of the body belong to a group called " $R$ " binders (15). $\mathrm{R}$ binders are closely related glycoproteins that differ one from another principally in their carbohydrate content $(16,17)$. An $\mathrm{R}$ binder from any one source contains several components when examined by isoelectric focusing (IEF) $(15,18,19)$, and it is sometimes difficult to decide whether an observed $\mathrm{R}$ binder is a distinct substance or part of another. Whereas $\mathrm{R}$ binders are common in blood cells and body fluids, several of them may have no role in $B_{13}$ transport but instead may simple be binders of $\mathrm{B}_{12}$. Although jargon, the term "R binder" is highly specific (15), and will be used here.

The present study was designed to resolve the controversy over the transport roles of the plasma carriers of $B_{12}$ in man. A subject, believed to be normal in his transport of $\mathrm{B}_{12}$, was given $\left[{ }^{57} \mathrm{Co}\right] \mathrm{B}_{12}$ orally in physiologic amounts. The specific activity was, however, sufficiently high to measure the mode of plasma transport for almost 2 mo. Each plasma sample was examined by at least two independent measures of the $\mathrm{B}_{12}$ bound to TC I, TC II, and TC III. Some of the data have been presented in abstract form (20).

\section{METHODS}

Subject. The subject was a 56-yr-old man with bronchiogenic carcinoma. An extensive investigation failed to reveal metastases, but on thoracotomy the tumor was found to be locally inoperable. He received radiation therapy from a cobalt source with considerable effect on the tumor. 1 mo after the completion of therapy he agreed to participate in the study. The need for the study and the procedures to be performed were explained in great detail, and written consent was obtained. His hematocrit was $38 \%$ and remained at that level; the rest of his complete blood count was normal. His serum $B_{12}$ and the amounts of the serum $B_{12}$ binders as labeled in vitro were normal before the study and when last examined 1 wk before termination of the study. 1 mo after the start of the study, there was evidence of local activity of the tumor. On day 45 a search for metastases was begun, and on day 57, 6 days after termination, neoplastic cells were found in the bone marrow. He died 17 days later; there was no autopsy.

${ }^{57} \mathrm{CoB}$ 18. The labeled cyancobalamin was purchased from Philips-Duphar, Petten, The Netherlands. Before use, it was checked for purity by electrophoresis and for $\mathrm{B}_{12}$ content by assay with Euglena gracilis (19). The dose contained $1.12 \mu \mathrm{g}$ of $\mathrm{B}_{13}$ and $229 \mu \mathrm{Ci}$ of ${ }^{57} \mathrm{Co}$. It was given in two aliquots $15 \mathrm{~min}$ apart, each with $30 \mathrm{ml}$ of water, when the patient was fasting. He began a normal breakfast 15 min after the second half. From previous studies in which both absorption and plasma levels were measured (21), the maximum plasma level of ${ }^{57} \mathrm{Co}$ suggested that the subject absorbed about $60 \%$ of the dose.

Sampling. Blood samples were taken at the intervals given below. To avoid any release of $B_{12}$ binders from blood cells to serum in vitro, all equipment was either plastic or siliconized, and the blood was separated at the bedside by immediate centrifugation. The plasma was removed and allowed to clot before removal of fibrin with wood applicators. Anticoagulants were avoided for most of the studies because their effect on the fractionation techniques was unknown. However, $5 \mathrm{ml}$ of EDTA plasma was collected at each sampling and ultimately found to be as usable as the "quick-spin" serum. The serum was frozen in $1-\mathrm{ml}$ aliquots and stored at $-20^{\circ} \mathrm{C}$ until use. During the early samplings, blood cells were collected and separated by the method of Natori (18). Any remaining granulocytes were removed from the erythrocyte preparation by passage through nylon fiber. The purity of the preparations was checked by stained smears.

Fractionation. The initial separation of TC II from the $\mathrm{R}$ binders in quick-spin serum was accomplished by the precipitation of TC II by $\left(\mathrm{NH}_{4}\right)_{2} \mathrm{SO}_{4}$; the method and the quality of separation have been described (19). The R component remaining in the supernate was further separated into $\alpha_{1}-\mathrm{R}$ and $\alpha_{2}-\mathrm{R}$ by a one-step batch anion exchange system (19). The $\alpha_{2}-\mathrm{R}$ eluted from the DEAE cellulose by phosphate buffer $(0.075 \mathrm{M}, \mathrm{pH}$ 6.2) corresponds to TC III and consists of those components of plasma $\mathrm{R}$ that are isoelectric at $\mathrm{pH} 3.3$ or greater (19). Samples were first fractionated in small batches as they were accumulated and then again all in a single run after the study had been completed. There was little difference between pairs. Because the second fractionation was simultaneous, it is the one reported below. The entire process was carried out in the cold.

It was known that with this system the $R$ fraction would be contaminated with a small amount of TC II (19). For the early samples where TC II was abundant as compared to $R$, this amount of contamination could have a significant effect on the observations. Therefore, $3 \mathrm{ml}$ of the 8-h sample was separated in $1-\mathrm{ml}$ aliquots, and the $\mathrm{R}$ fraction was further examined by gel filtration. Of the total TC II $\left[{ }^{57} \mathrm{Co}\right] \mathrm{B}_{13}$ in the blood at $8 \mathrm{~h}, 3.3 \%$ was recovered in the $R$ fraction. This correction figure was applied to the 4,8 , and 24 -h samples.

$5-\mathrm{ml}$ aliquots of each sample of serum were fractionated by gel filtration on Sephadex G-200 (19). The entire process was carried out in the cold. Distinct peaks of both TC II and R were evident for the first 3 days of samples. After that time and up to 31 days, there was sufficient TC II- $B_{13}$ to count, but the limits of the TC II peaks were indistinct, making precise quantitation difficult. The TC II recovered from the gel filtrations of samples up to and including that of day 3 was tested by reaction with antiTC II as described previously (22). Subsequently, the activity of TC II was too low to permit this step.

IEF was the final evaluation of the $R$ binders. The technique, adapted from that of Stenman and Gräsbeck (23), has been described (19). Initially, the $\mathrm{R}$ component as recovered from the gel filtration of each sample was concentrated with an Amicon PM-10 membrane (Amicon Corp., Scientific Sys. Div., Lexington, Mass.) and used for IEF. The protein content exceeded the capacity of the IEF for a good focus, and the long preparation time was of some concern. For repeat of the IEF's enough EDTA plasma of 4-h-7-day samples remained. The bulk of the plasma protein was removed from $5.6 \mathrm{ml}$ of plasma by precipitation with $2.25 \mathrm{M}\left(\mathrm{NH}_{4}\right)_{2} \mathrm{SO}_{4}$ at $\mathrm{pH}$ 4.8. This modification of the technique was designed specifically to reduce the total protein to a minimum without loss of $\mathrm{R}$ binder; about $40 \mathrm{mg}$ of protein was included in each IEF. Much of the TC II was also removed, and any remaining was of no concern since it would move to the cathode during the 5 -day focus (24). The sample replaced an equal volume of water of the light solution for loading into the IEF 
chamber; it was kept cold during all steps. Methyl red was incorporated into the focus as an indicator. For the critical parts of the IEF, fractions of $0.5 \mathrm{ml}$ were collected and counted, but pools of $1.5 \mathrm{ml}$ were sometimes made subsequently for more accurate counts. The $\mathrm{pH}$ was measured at room temperature on pools of 1-2 ml by an Accumet model 520 digital $\mathrm{pH}$ meter, standardized at $\mathrm{pH}$ 4.0 (Fisher Scientific Co., Pittsburgh, Pa.).

Counting of ${ }^{57} \mathrm{Co}$. The products of all fractionations were counted in a refrigerated Packard gamma scintillation spectrometer (Packard Instrument Co., Inc., Downers Grove, Ill.). Counting volumes ranged from 0.5 to $5 \mathrm{ml}$, and count times ranged from 1 to $100 \mathrm{~min}$ according to the activity. Individual specimens were counted to a $5 \%$ or less counting error, but some of the fractions from IEF were counted to an error of $10-20 \%$. All radioactivity was corrected for decay to day 1 .

$B_{18}$ Assay. The total native $\mathrm{B}_{12}$ bound to the $\mathrm{R}$ components was determined on the IEF products of the day 7 sample. The fractions from the IEF chamber were combined into four pools. Each pool was treated as follows to remove small ions, ampholytes, and glycerol that might alter the growth of the assay organism. The pool was put into a 50-ml Amicon Diaflow with a PM-10 membrane (passes particles smaller than mol wt 10,000) and brought to $50 \mathrm{ml}$ with cold, glass-distilled water. The membrane was first treated with $1.0 \mathrm{ml}$ of a $1: 100$ dilution of $B_{12-}$ deficient serum to minimize adherence of the protein. Contents were concentrated to less than $5 \mathrm{ml}$, and the process was repeated twice. Each washed and concentrated pool was assayed for $\mathrm{B}_{12}$ content by bioassay with Euglena gracilis (19).

General. The proteins, TC II or R binder, were always measured experimentally by the $\left[{ }^{57} \mathrm{Co}\right] \mathrm{B}_{12}$ bound to them; the amounts were too small to detect in any other way. Where measurements were made on either plasma or serum, the distinction is so stated. Plasma is also used in the text where describing in vivo events.

\section{RESULTS}

All measurements, with three exceptions as noted, were of the ${ }^{67} \mathrm{Co}$ label that reached the binding proteins through absorption of the $\left[{ }^{57} \mathrm{Co}\right] \mathrm{B}_{12}$; no label was added to the serum or plasma in vitro. The label, therefore, should have represented first any native $B_{12}$ being absorbed, and once equilibrium had been reached, the transport of the total plasma $B_{12}$. The peak plasma activity was reached at $8 \mathrm{~h}$ after intake as would be expected from many previous studies. The plasma radioactivity at that time represented $5 \mathrm{pg}$ of $\mathrm{B}_{12}$ or slightly less than $1 \%$ of the total plasma $B_{12}$ of this subject. About $0.35 \%$ of available TC II and $0.31 \%$ of available $R$ were saturated. At day 31 there was about $0.3 \mathrm{pg}\left[{ }^{57} \mathrm{Co}\right] \mathrm{B}_{12} / \mathrm{ml}$ plasma. Quantitative data are given in picograms per milliliter of serum in Fig. 1 and as percent of $\left[{ }^{57} \mathrm{Co}\right] \mathrm{B}_{12}$ present in Table I.

Transport by TC II. As measured by either gel filtration or by $\left(\mathrm{NH}_{4}\right)_{2} \mathrm{SO}_{4}$ precipitation, TC II was unquestionably the dominant carrier of the recently $a b-$ sorbed $B_{12}$ (Fig. 1 and Table I). The identity of the TC II was confirmed not only by two distinct methods

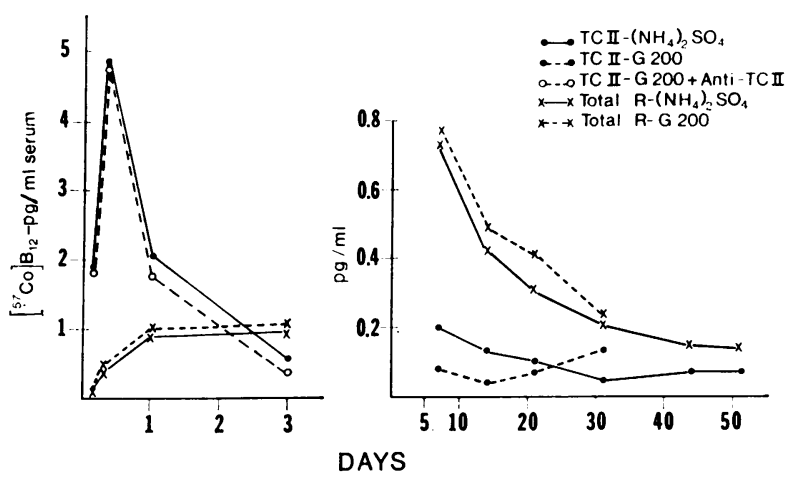

FIGURE 1 The binding of the absorbed $\left[{ }^{57} \mathrm{Co}\right] \mathrm{B}_{12}$ at different times after intake. The TC II- $B_{12}$ and the total R-B were measured by both gel filtration and by the $\left(\mathrm{NH}_{4}\right)_{2} \mathrm{SO}_{4}$ technique and for the first four samples, the TC II was confirmed by reaction with anti-TC II.

of measurement but also by reaction with specific antibody (Fig. 1). For each sample tested up to day 3, all of the TC II fraction recovered from the gel filtration reacted with the antibody. After day 3 , the values obtained for TC II-B ${ }_{12}$ by $\left(\mathrm{NH}_{4}\right)_{2} \mathrm{SO}_{4}$ were probably the more reliable. From one fifth to one third of the plasma $\mathrm{B}_{12}$ was carried by TC II. This fraction remained more or less constant from wk 1 to 4 and then increased slightly as measured by both techniques. A cyclic effect of labeled total plasma $B_{12}$ had been noted in earlier studies (21).

Transport by plasma $R$. The label on total $\mathrm{R}$ increased slowly during the first $24 \mathrm{~h}$ as measured by both techniques (Fig. 1). The peak may have been missed but probably occurred between days 1 and 3 . By that time, $\mathrm{R}$ was the dominant carrier of the $\mathrm{B}_{12}$ label

TABLE I

Binding Patterns of $\left[{ }^{67} \mathrm{Co}\right] B_{12}$ after Absorption

\begin{tabular}{ccccc}
\hline Time after intake & TC II & Total R & $\alpha_{2}-\mathbf{R}$ & $\alpha_{1}-\mathbf{R}$ \\
\hline & \multicolumn{2}{c}{ \% of total bound } & \% of total $R$ \\
$4 \mathrm{~h}$ & 95 & 5 & 52 & 48 \\
$8 \mathrm{~h}$ & 92 & 8 & 45 & 55 \\
$24 \mathrm{~h}$ & 69 & 31 & 42 & 58 \\
3 days & 35 & 65 & 40 & 60 \\
7 days & 22 & 78 & 39 & 61 \\
14 days & 24 & 76 & 36 & 64 \\
21 days & 25 & 75 & 34 & 66 \\
31 days & 20 & 80 & 31 & 69 \\
44 days & 31 & 69 & 38 & 62 \\
51 days & 33 & 67 & 40 & 60 \\
In vitro label & 91 & 9 & 76 & 24 \\
(by (NH4) 2 SO4-DEAE) & & & & \\
In vitro label & 94 & 6 & & \\
(by G-200) & & & & \\
\hline
\end{tabular}

[ ${ }^{37} \mathrm{Co}_{0} \mathrm{~B}_{12}$ was determined by the $\left(\mathrm{NH}_{4}\right)_{2} \mathrm{SO}_{4}-\mathrm{DEAE}$ system. $\alpha_{2}-\mathrm{R}$ is that fraction eluted from the DEAE cellulose with $0.075 \mathrm{M}$ buffer, and $\alpha_{1}-\mathrm{R}$ is the fraction retained. 
and remained so, carrying two thirds to four fifths of the total. Fig. 2 shows the distribution of the label on the two transport proteins as separated by gel filtration at 4 and $8 \mathrm{~h}$ after intake.

Subdivision of serum $R-B_{18}$. One approach was to split R-B $\mathrm{B}_{12}$ into two components by the technique based on anion exchange (Table I). $\alpha_{2}-\mathrm{R}$ corresponds roughly to TC III and $\alpha_{1}-\mathrm{R}$ to TC I (19). With the possible exception of the 4-h sample where activity was the lowest, binding to $\alpha_{1}-\mathrm{R}$ predominated. This was the exact reverse of the pattern found when $B_{12}$ was added to the subject's quick-spin serum in vitro (Table I) or to that of other normal subjects (19).

Fractionation of $R-B_{1}$ by $I E F$. The $\mathrm{R}$ component of the 4-h, 8-h, 24-h, 3-day, and 7-day samples were all examined by IEF. There were quantitative differences reflecting the changing levels of total $R$ with time, but the distribution of the label was identical in all five samples. Four of the IEF's are illustrated in Fig. 3. Like all $\mathrm{R}$ binders studied to date (15), the $\mathrm{R}$ that carried $B_{12}$ bound naturally was isoelectrically heterogeneous. The main component was isoelectric at $\mathrm{pH}$ 3.233.31, but components peaking at just under and just over $\mathrm{pH} 3.0$ were also present. This pattern was in contrast to that obtained when $\left[{ }^{67} \mathrm{CO}\right] \mathrm{B}_{12}$ was added to the subject's quick-spin serum in vitro and then focused (Fig. 4). The same components were labeled, but in addition there were components isoelectric at $\mathrm{pH} 3.66$ and 4.03. Similar components are common in the ma-

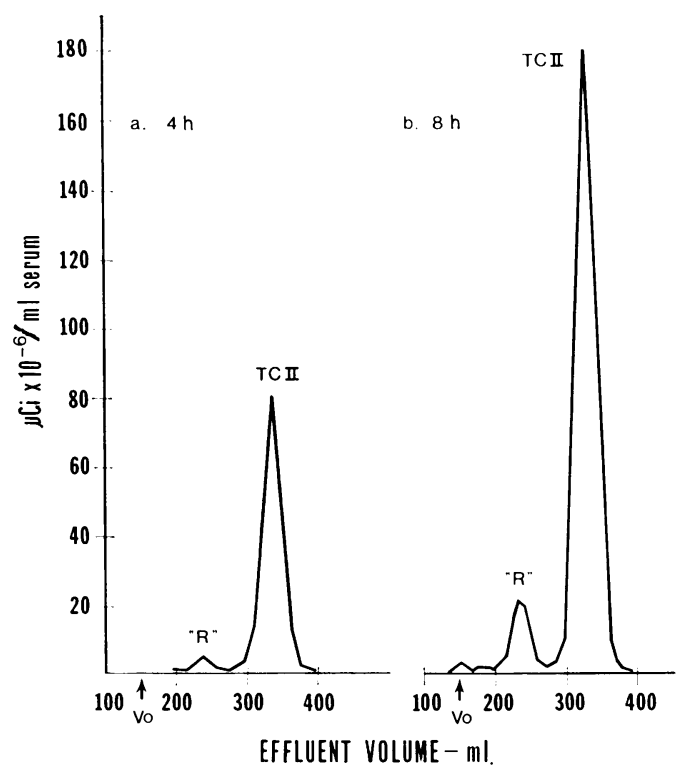

Figure 2 Gel filtration on Sephadex G-200 of the 4- and 8-h samples. The elution volumes of TC II- $B_{12}$ and total $\mathrm{R}-\mathrm{B}_{12}$ had been determined by previous calibration of the columns.
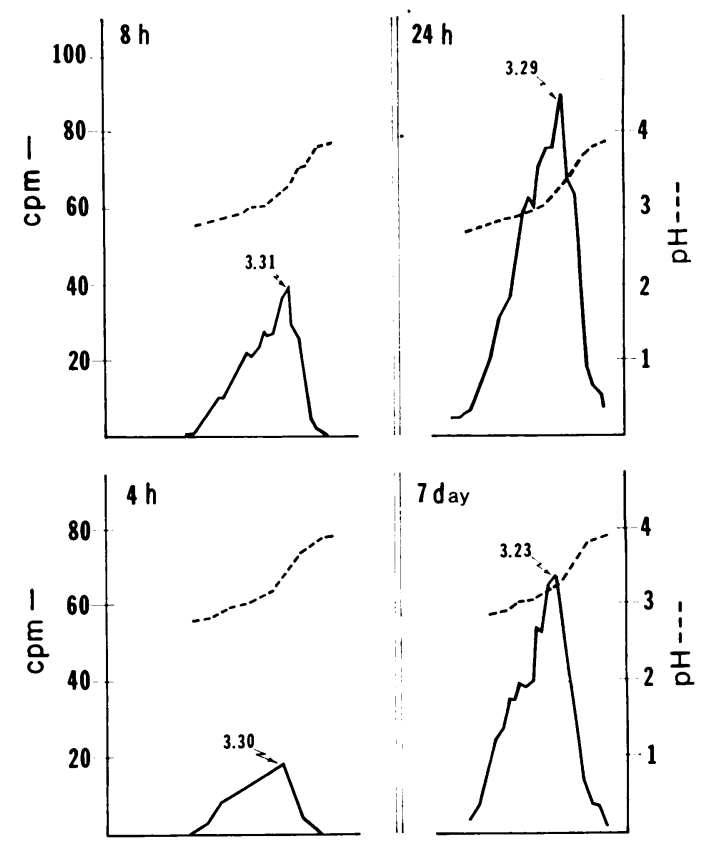

FIGURE 3 IEF of the total $\mathrm{R}$ of $5-6 \mathrm{ml}$ of EDTA plasma from the four samplings indicated. Radioactivity is plotted against the $\mathrm{pH}$. The numbers on the face of the graphs are the $\mathrm{pH}$ at which the main peak was isoelectric. There was no radioactivity focusing at $\mathrm{pH}$ 's higher than those illustrated.

jority of $\mathrm{R}$ binders $(15,18)$. In some sera labeled in vitro a peak at 3.34 predominates, but more often the dominant component has been at $\mathrm{pH} 3.65$ (19). For comparison, Fig. 4 also illustrates an IEF of the media labeled in vitro from a 24-h culture of the subject's granulocytes. The main component was isoelectric at $\mathrm{pH} 3.67$ with a lesser peak at $\mathrm{pH}$ 3.95. No identifiable components focused at a $\mathrm{pH}$ of less than 3.0. Lysed granulocytes from the subject also labeled in vitro showed an almost identical IEF (not illustrated) except that a small peak could be identified at $\mathrm{pH}$ 3.34. The in vivo label on granulocytes was too low to permit IEF. The binding pattern of the subject's lysed granulocytes was the same as that of 10 other granulocyte preparations.

Four pools of the components obtained by the IEF of the day $7 \mathrm{R}$ were assayed for total native $B_{1 s}$ content. As shown in Fig. 5, the peak amount of native $B_{12}$ was in the pool focusing between $\mathrm{pH} 3.07$ and 3.50 . There was surprisingly good correlation between the distributions of native plasma $B_{12}$ as measured by bioassay and that labeled through absorption of $\left[{ }^{57} \mathrm{Co}\right] \mathrm{B}_{12} 7$ days before.

The label in other fluids and cells. Radioactivity could be detected in a preparation of pure erythrocytes beginning at day 1 , and reaching a peak on day 7;

\section{8 \\ C. A. Hall}


thereafter, it declined (Table II). Whereas appearance of the label in granulocytes was reported in the abstract of this study (20), the data, for technical reasons, were not precise. Saliva when first collected on day 1 contained some activity, but it disappeared by day 3-7. The label may have represented contamination of the mouth by the oral dose rather than a label of the saliva as it was secreted.

\section{DISCUSSION}

The observation that TC II carried more than $90 \%$ of the recently absorbed $\mathrm{B}_{12}$ was completely compatible with all but one (14) of the earlier studies of a similar nature $(1-3,10)$. The present study was somewhat more conclusive because it identified TC II by three independent techniques, all superior to that used in the earlier human studies. Moreover, the dynamics of TC II- $\mathrm{B}_{13}$ were extended beyond the $24-48 \mathrm{~h}$ of the initial studies into the 2 nd mo when one third to one fourth of the labeled $\mathrm{B}_{12}$ was still being carried by TC II. These dynamic studies, coupled with the static observation that a similar fraction of native $B_{12}$ was carried by TC II (5), demonstrate that the function of TC II does not end once absorption is complete.

Transport by the $\mathrm{R}$ component of plasma did not reach its maximum until more than 1 day after intake
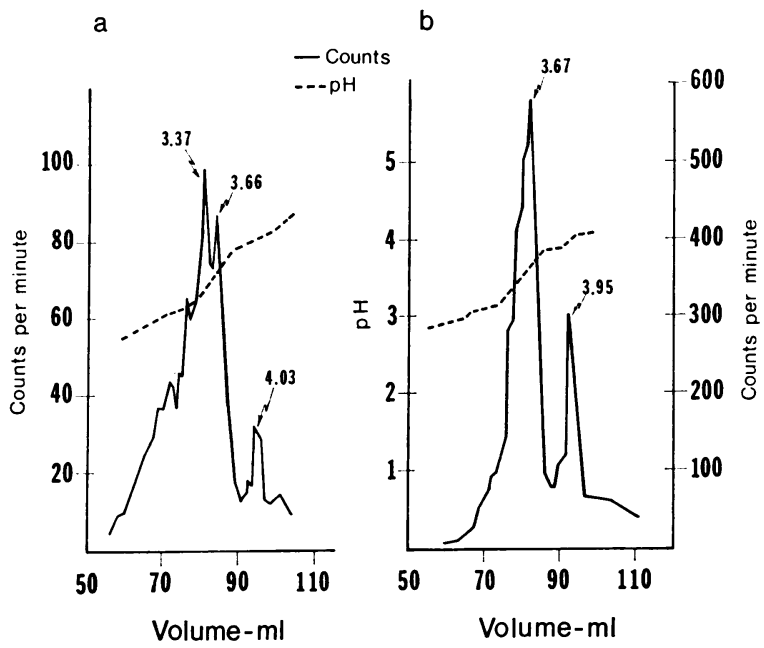

FIGURE $4 a$. IEF of the $\mathrm{R}$ component from quick-spin serum labeled to capacity with $\left[{ }^{57} \mathrm{Co}\right] \mathrm{B}_{12}$ in vitro; the sample was collected before the study. The $R$ component was separated from the serum by the same technique as used for the studies of Fig. 3, and the conditions of focus were identical. $b$. IEF of the $B_{12}$ binder released from the subject's granulocytes during a 24-h culture in minimal essential media, Joklik-modified with $2 \%$ bovine serum albumin (Grand Island Biological Co., Grand Island, N.Y.). The $R$ binder was labeled to capacity with $\left[{ }^{57} \mathrm{Co}\right]-$ $B_{12}$ after the medium was separated from the cells and focused directly without further processing.

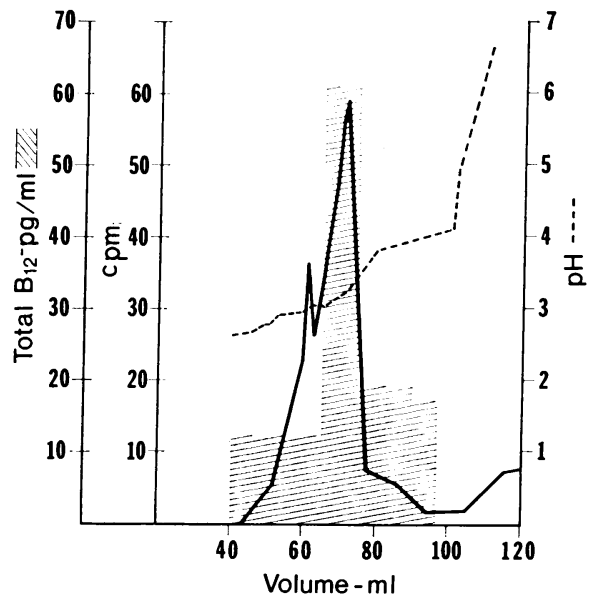

FIGURE 5 The distribution on IEF of the total, native $B_{12}$ bound to the $\mathrm{R}$ components of the day 7 plasma; fractions were combined into four pools for bioassay. The size and extent of the pools are indicated horizontally and the concentration of $B_{12}$ is shown vertically. The plot of radioactivity differs somewhat from that of Fig. 3 since this figure shows the counts from $0.5-\mathrm{ml}$ fractions as collected, while in Fig. 3 fractions were combined in threes $(1.5 \mathrm{ml})$ for a higher count rate.

although the total label in the plasma peaked at $8 \mathrm{~h}$. A slow buildup of TC I-B $\mathrm{B}_{12}$ had also been observed in the past $(3,8)$. Hom, who used a totally different approach, also found binding of $B_{12}$ to $R$ binders to be a time-dependent process (11). When TC II- $B_{12}$ was injected intravenously into man, the complex cleared from the circulation at the expected rate while appearance of the label bound to $R$ binders was delayed. $R$ labeling was detectable at $4 \mathrm{~h}$ after injection, reached a near maximum at $8 \mathrm{~h}$, and changed little at $24 \mathrm{~h}$. Given the differences in techniques and mode of entry of the $B_{12}$, the timing of the $\mathrm{R}$ label was similar in the present study and that of Hom (11). Complexing of total R with free $B_{12}$ in portal blood could not give the patterns of Fig. 3 but instead would give the pattern of Fig. $4 a$.

One of the more significant of the present observations allows a description of the plasma $R$ that carries $B_{12}$ naturally. From the earliest studies $(1,9)$, it appeared that the carrier was an unusually acidic plasma protein.

TABLE II Content of $\left[{ }^{67} \mathrm{Co}\right] B_{12}$

\begin{tabular}{ccccc}
\hline & \multicolumn{4}{c}{ Day after intake } \\
\cline { 2 - 5 } Substance & 1 & 3 & 7 & 14 \\
\hline $\begin{array}{c}\text { Erythrocytes, } \\
\mu C i \times 10^{-9} / 10^{6} \mathrm{cells} \\
\begin{array}{c}\text { Saliva, } \mu \mathrm{C} i \times 10^{-3} / \mathrm{ml} \\
\text { S }\end{array}\end{array}$ & 0.06 & 0.40 & 17.30 & 3.45 \\
\hline
\end{tabular}


Now with better techniques and labels of higher activity, those observations are confirmed; both the anion exchange technique and IEF used here showed the functioning $\mathrm{R}$ to be acidic. Moreover, it appeared that the composition of the carrier remained unchanged from $4 \mathrm{~h}$ to 51 days. The low isoelectric points of the $\mathrm{R}$ components found to be carrying total, native $B_{12}$ at day 7 support the observations made from the $\left[{ }^{57} \mathrm{Co}\right] \mathrm{B}_{12}$ label.

The composition of native $R$ in plasma differed from that of the total $R$ of serum as it was labeled in vitro even when blood cells, which might release the more basic $\mathrm{R}$ components, were removed immediately. The unsaturated $R$ of serum resembled a combination of the functioning $\mathrm{R}$ of plasma plus components that were isoelectric at $\mathrm{pH}$ greater than 3.5 and that carried little if any $B_{12}$ naturally. One cannot escape the conclusion that the unsaturated $\mathrm{R}$ of serum comes from more than one source and can be considered a combination of at least two substances. The definition of TC I can now be updated from the original (10) as the R-type binder in plasma that carries part but not all of the plasma $\mathrm{B}_{12}$ during metabolism and that consists of several components isoelectric between $\mathrm{pH} 2.9$ and 3.35.

Although IEF appears to be the preferable method of identification of $\mathrm{R}$ binders, the anion exchange system was also used because it was a check on IEF and permitted continuance of the studies as the radioactivity declined to low levels. The dividing point between $\alpha_{1}$ and $\alpha_{2}$ in this system comes, unfortunately, at about $\mathrm{pH} 3.3$ (19), and some of the $\mathrm{pH} 3.3$ component does go with the $\alpha_{2}-\mathrm{R}$. With the knowledge gained from the present study, it may be possible to redesign the system to give a more physiologic cut at $\mathrm{pH} 3.5$. Fig. 3 probably does not give a true visualization of TC $\mathrm{I}$. The arrangement of molecules coming from the IEF chamber is a function not only of their isoelectric points but also of the arrangement of the ampholytes and the conductivity throughout the chamber. The gradient, the best one available, was shallow below $\mathrm{pH} 3.2$ and steep between $\mathrm{pH} 3.2-3.8$, producing broad focusing in the lower ranges and sharp focusing in the upper. It may be that the functioning $R$, TC I, consists of a myriad of components, possibly from multiple sources, varying only slightly from one another in sialic acid content but with isoelectric points ranging between 2.9 and 3.35.

Neither by IEF nor by the anion exchange technique was there any evidence during the 50 days of study of natural binding to an R-type binder of $\alpha_{2}$ mobility, TC III. The observations do not exclude the possibility that such a binder may be functional under some other conditions or that a small amount of $\alpha_{2} \mathrm{R}-\mathrm{B}_{12}$ is formed and cleared without being detected.

There was no attempt to measure turnover rates in the present study. As in earlier studies (21), the pres- ent data suggest that absorbed $B_{12}$ does not reach full equilibrium with the $B_{12}$ of the rest of the body until sometime after 30 days. The entry and exit of $B_{12}$ to and from erythrocytes deserves further exploration. The present study and two previous ones in the rabbit (25) and in man (21) showed peak labeling in plasma to be about 1 wk after intake. The $B_{12}$ did not remain in the cells for their entire life span but declined promptly. Harrison (26) has observed the peak native $\mathrm{B}_{12}$ content of erythrocytes to occur simultaneously with the peak reticulocytosis that had been induced by treatment of deficient erythropoiesis. The concept of many years that TC I originates from granulocytes is not supported by the present data. By IEF, TC I did not at all resemble the $\mathrm{R}$ binder in the subject's granulocytes or the $\mathrm{R}$ binder released when the granulocytes were cultured.

\section{ACKNOWLEDGMENTS}

The author wishes to express his appreciation for assistance in the many parts of this technically complex and demanding study, especially to Mr. James Begley, who devised some of the crucial techniques. The others were: Dr. C. Richard Savage, Mrs. Pamela D. Green, and Mrs. Ann Marie Meehan. Also acknowledged is the contribution of Mr. J. R., the most essential of all.

This work was supported in part by V. A. research project no. 3390-01.

\section{REFERENCES}

1. Hall, C. A., and A. E. Finkler. 1963. A second vitamin $\mathrm{B}_{12}$-binding substance in human plasma. Biochem. Biophys. Acta. 78: 233-236.

2. Hall, C. A., and A. E. Finkler. 1966. Function of transcobalamin II: a $\mathrm{B}_{12}$ binding protein in human plasma. Proc. Soc. Exp. Biol. Med. 123: 55-58.

3. Rappazzo, M. E., and C. A. Hall. 1972. Cyanocobalamin transport proteins in canine plasma. Am. J. Physiol. 222: 202-206.

4. Allen, R. H., and P. W. Majerus. 1972. Isolation of vitamin $B_{12}$-binding proteins using affinity chromatography. III. Purification and properties of human plasma transcobalamin II. J. Biol. Chem. 247: 7709-7717.

5. Benson, R. E., M. E. Rappazzo, and C. A. Hall. 1972. Late transport of vitamin $B_{12}$ by transcobalamin II. J. Lab. Clin. Med. 80: 488-495.

6. Hakami, N., P. E. Neiman, G. P. Canellos, and J. Lazerson. 1971. Neonatal megaloblastic anemia due to inherited transcobalamin II deficiency in two siblings. N. Engl. J. Med. 285: 1163-1170.

7. Hitzig, W. H., U. Dohmann, H. J. Pluss, and D. Vischer. 1974. Hereditary transcobalamin II deficiency: clinical findings in a new family. J. Pediatr. 85: 622628.

8. Hall, C. A. 1973. Congenital disorders of vitamin $B_{12}$ transport and their contribution to concepts. Gastroenterology. 65 : 684-686.

9. Mendelsohn, R. S., D. M. Watkin, A. P. Horbett, and J. L. Fahey. 1958. Identification of the vitamin $B_{12^{-}}$ binding protein in the serum of normals and of patients with chronic myelocytic leukemia. Blood. 13: 740-747. 
10. Hall, C. A., and A. E. Finkler. 1965. The dynamics of transcobalamin II. A vitamin $B_{12}$ binding substance in plasma. J. Lab. Clin. Med. 65: 459-468.

11. Hom, B. L. 1967. Plasma turnover of ${ }^{57}$ Cobalt-vitamin $\mathrm{B}_{12}$ bound to transcobalamin I and II. Scand. J. Hematol. $4: 321-332$.

12. Gizis, E. J., S. N. Arkun, I. F. Miller, G. Choi, M. F. Dietrich, and L. M. Meyer. 1969. Plasma clearance of transcobamin I- and transcobalamin II-bound $\mathrm{Co}^{57}$ vitamin $B_{12}$. J. Lab. Clin. Med. 74: 574-580.

13. Carmel, R., and V. Herbert. 1969. Deficiency of vitamin $\mathrm{B}_{12}$-binding alpha globulin in two brothers. Blood. 33: $1-12$.

14. England, J. M., H. G. M. Clarke, M. C. Down, and I. Chanarin. 1973. Studies on the transcobalamins. $\mathrm{Br}$ J. Haematol. 25 : 737-749.

15. Stenman, U. H. 1975. Vitamin B-12 binding proteins of R-type, cobalophilin. Characterization and comparison of cobalophilin from different sources. Scand. J. Hematol. 14 : 91-107.

16. Allen, R. H., and P. W. Majerus. 1972. Isolation of vitamin $\mathrm{B}_{12}$-binding proteins using affinity chromatography. II. Purification and properties of a human granulocyte vitamin $\mathrm{B}_{12}$-binding protein. J. Biol. Chem. 247: 7702-7708.

17. Burger, R. L., and R. H. Allen. 1974. Characterization of vitamin $\mathrm{B}_{12}$-binding proteins isolated from human milk and saliva by affinity chromatography. J. Biol. Chem. 249: 7220-7227.
18. Natori, H. 1971. Physiocochemical analyses of vitamin $\mathrm{B}_{12}$ binding proteins in sera, gastric juice, and leucocytes. Tumor Res. 6: 1-79.

19. Begley, J. A., and C. A. Hall. 1975. Measurement of vitamin $\mathrm{B}_{12}$-binding proteins of plasma. I. Technique. II. Interpretations of patterns in disease. Blood. 45: 281-286, 287-293.

20. Hall, C. A. 1974.. Dynamics of plasma transport proteins of vitamin $\mathrm{B}_{12}$. 17th Annual Meeting, American Society of Hematology, 7-10 Dec. 1974, Atlanta, Ga. Grune \& Stratton, Inc., New York. 97. (Abstr.)

21. Hall, C. A. 1964. Long-term excretion of $\mathrm{Co}^{57}$-vitamin $\mathrm{B}_{12}$ and turnover within the plasma. Am. J. Clin. Nutr. $14: 156-162$.

22. Finkler, A. E., P. D. Green, and C. A. Hall. 1970. Immunological properties of human vitamin $\mathrm{B}_{12}$ binders. Biochem. Biophys. Acta. 200: 151-159.

23. Stenman, U.-H., and R. Gräsbeck. 1972. Gradients for isoelectric focusing at low $\mathrm{pH}$. Biochem. Biophys. Acta. 286: 243-251.

24. Stenman, U. H. 1974. Characterization of $\mathrm{R}$ type vitamin $\mathrm{B}_{12}$ binding proteins by isoelectric focusing. Scand. J. Hematol. 13: 129-134.

25. Rosenthal, H. L. 1959. The uptake and turnover of radioactive vitamin $B_{12}$ in rabbit tissues. J. Nutr. 68: 297-311.

26. Harrison, R. J. 1971. Vitamin $B_{12}$ levels in erythrocytes in anaemia due to folate deficiency. Br. J. Haematol. 20: $623-628$. 